\title{
Religião e participação política: instituições religiosas e o desenvolvimento de habilidades civicas
}

\author{
Religion and political participation: religious institutions and the \\ development of civic skills
}

\section{Ednaldo Aparecido Ribeiro Alice Vila Nova Procopiuk Walter}

\section{Resumo}

Na esfera política, passamos atualmente por um momento de expressão pública do religioso, fenômeno que tem chamado a atenção de pesquisadores brasileiros, principalmente no que diz respeito aos impactos da religiáo sobre o comportamento eleitoral dos indivíduos. É preciso reconhecer, entretanto, que o voto não é a única forma de participação política dentro do sistema democrático. Diante disto, este artigo buscou contribuir para a identificação da influência das instituiçóes religiosas na política brasileira, verificando em que medida as principais religióes brasileiras estáo relacionadas com a participação política, não apenas no que se refere às formas eleitorais, mas estendendo-se também às formas não convencionais ou de protesto. $\mathrm{O}$ material empírico utilizado na pesquisa foi produzido pelo Projeto de Opinião Pública da América Latina (LAPOP) de 2012. Os resultados encontrados indicam que o ativismo religioso exerce efeito positivo sobre o engajamento cívico do brasileiro.

\section{Palavras-chave}

Participação Política; Religiáo; Comportamento Político.

\begin{abstract}
The political sphere is currently going through a time of public religious expression, phenomenon that has attracted the attention of several researchers, particularly regarding to the impacts of the religion on the electoral behavior of individuals. However, despite its pertinence, voting is not the only way of political participation in the democratic system. From that, this study aimed to contribute to the identification of the influence of religious institutions on Brazilian politics, checking to what extent the main Brazilian religions are related to political participation, not only regarding the electoral forms, but also extending the unconventional or protest forms. The empirical data used in the study was produced by the Public Opinion Project of Latin America (LAPOP) of 2012. The results indicate that religious activism has a positive effect on civic engagement in Brazil.
\end{abstract}

\section{Keywords}

Political Participation; Religion; Political Behavior. 


\section{Introdução}

Desde as eleiçóes presidenciais de 2010, diversos pesquisadores brasileiros têm se proposto a analisar tanto os candidatos que instrumentalizam eleitoralmente sua religiosidade, quanto a busca dos candidatos que se identificam como laicos pelo apoio eleitoral de autoridades eclesiásticas e organizaçóes religiosas. $\mathrm{O}$ foco das discussôes voltou-se, quase que inteiramente, para a inserção dos grupos religiosos, principalmente dos evangélicos, na política eleitoral e partidária.

Contudo, é amplamente reconhecido que toda a história nacional é marcada pela presença da religião na esfera pública, estando presente na política desde nossa colonização. Em todos esses momentos é possível ver a persistência, vitalidade e saúde da religiáo ao longo da história nacional. Como bem aponta Paula Montero (2012), é preciso reconhecer que a Igreja Católica teve um importante papel na concepção e estabilização política dos direitos individuais e na construção de um modelo de sociedade civil, e que em nosso país as religiōes estiveram presentes historicamente na construção e gestáo do espaço público, influenciando fortemente as áreas da educação, saúde e assistência social sob o consentimento e apoio do próprio Estado. Observando a história brasileira, é possível notar que o processo de separação entre Igreja e Estado, que até os dias de hoje levanta questionamentos, não teve como produto o declínio e o fim da religião, mas sim a produção e a legitimação de novas formas religiosas e a continuidade de sua ação na política (GIUMBELLI, 2002; MONTERO, 2006).

A compreensão adequada sobre a relação entre política e religiáo deve contemplar a dimensão institucional, acerca das influências das denominaçôes sobre o funcionamento do Estado, mas também dimensóes ligadas ao comportamento individual dos cidadáos. Nesse terreno, pesquisas recentes têm se dedicado à identificação de componentes religiosos na explicação das decisōes tomadas pelos eleitores em pleitos de diferentes esferas e para diferentes cargos (PIERUCCI, 2011; ORO, 2001 e 2003; ORO e MARIANO, 2010; BOHN, 2004). Mais escassas são as pesquisas sobre comportamentos políticos que se situam fora dos limites eleitorais e, diante dessa constatação, desenvolvemos uma pesquisa que procurou investigar o efeito da filiação e do ativismo religioso sobre diferentes modalidades de participação política entre os cidadãos brasileiros.

O presenta artigo expóe os principais resultados dessa investigaçáo e, para tanto, está divido em quatro partes, além dessa introdução: na primeira revisamos rapidamente a literatura que trata da relaçáo entre comportamento político e instituiçóes religiosas, dando destaque à teoria de Voluntarismo Cívico de Sidney 
Verba, Kay L. Schlozman e Henry E. Brady (1995); na segunda, apresentamos os procedimentos metodológicos utilizados na pesquisa; na sequência, são apresentados e discutidos os resultados encontrados; por fim, tecemos algumas consideraçóes finais acerca dos achados da pesquisa.

\section{Comportamento politico e instituições religiosas}

Diversos autores se propuseram a discutir a questão da presença da religião na esfera pública, porém, como nossa intenção neste artigo é analisar a relação entre instituiçôes religiosas e participação política, não pretendemos aqui fazer um longo inventário sobre a literatura politológica que se dedica à interface religiáo/política, de modo que focalizamos apenas as pesquisas acerca da influência das instituiçóes religiosas na formação, mobilização e engajamento político dos indivíduos.

Dentre os pesquisadores mais conhecidos e citados encontram-se Sidney Verba, Kay L. Schlozman e Henry E. Brady. Esses autores possuem diversos textos que abordam a relação religião/política, dentre eles Voice and Equality (1995), no qual desenvolvem o Modelo de Voluntarismo Cívico com a finalidade de explicar a participação política. Buscando entender o impacto organizacional da igreja no engajamento político dos americanos, os autores destacam o papel dessa instituição no desenvolvimento de habilidades cívicas, definidas como capacidades organizacionais e comunicacionais que permitem o engajamento em atividades nas quais as pessoas podem expressar sua voz no processo político. Tais habilidades seriam recursos que facilitariam a participação política, quando empregadas em favor de suas causas.

As igrejas, instituiçóes não políticas da vida adulta, promoveriam a chance de praticar tais habilidades, isto é, seriam lugares nos quais os cidadáos podem desenvolver características que poderiam torná-los ativos politicamente. Segundo Verba, Schlozman e Brady (1995), a filiação religiosa tem como diferencial o fato de não ser estratificada por renda, etnia ou gênero, o que permite que a divisão de oportunidades para o desenvolvimento de habilidades cívicas seja relativamente igual entre os seus membros. Assim, devido a essa distribuição de oportunidades, as instituições religiosas parecem ter o potencial de reforçar os recursos políticos disponíveis aos cidadáos desprivilegiados.

Percebendo o papel significativo que as igrejas desempenham como instituiçóes espirituais e sociais, os autores dedicam-se a examinar a sua função, enquanto geradoras de envolvimento político, entre os afro-americanos e latinos nos 
Estados Unidos. Dentre outros achados, encontraram que os afro-americanos são mais ativos que os latinos e os brancos na frequência em atividades da igreja, no tempo gasto em atividades educacionais, sociais e de caridade dentro da igreja, e na contribuição de fundos. Além disso, verificaram que os latinos, apesar de possuírem um alto nível de frequência à igreja, possuem baixo nível de envolvimento em atividades educacionais, de caridade e sociais ligadas às suas igrejas, o que pode estar relacionado com o fato de serem mais propícios ao Catolicismo do que ao Protestantismo (VERBA, SCHLOZMAN e BRADY, 1995).

Segundo os autores, essas diferenças comportamentais podem estar ligadas a características organizacionais, já que as igrejas católicas e protestantes diferem em diversas dimensóes. Essas últimas tendem a ser menores, a maioria das suas denominaçôes permite uma maior participação na liturgia e em grande parte estão organizadas em bases congregacionais em vez de hierárquicas como as igrejas católicas. Para os autores, os dados encontrados entre os latinos nos Estados Unidos demonstram que o tipo de igreja que o indivíduo faz parte afeta a aquisição de habilidades cívicas, tendo assim um efeito mediado sobre o seu padrão de atuação política.

As instituiçóes religiosas, contudo, não apenas contribuiriam para o desenvolvimento de habilidades cívicas, como também funcionariam como lugar de recrutamento e de estímulo para o engajamento político. Por meio de sua rede de contatos, os indivíduos seriam recrutados para a participaçáo. $\mathrm{O}$ envolvimento em igrejas traria também a exposição a conversas, a mensagens e a palpites políticos, mesmo em contextos institucionais que não tenham uma conexão direta com a política.

Aqui, como medida a ser testada entre afro-americanos, latinos e brancos, os autores utilizam a frequência em reuniōes na igreja para discutir algum assunto político nacional ou local e a frequência com que o clérigo discute assuntos políticos no púlpito. A diferença encontrada entre católicos e protestantes em termos de recrutamento político e exposição a mensagens políticas é pequena, se comparada com a prática de habilidades cívicas. Já entre afro-americanos e os outros dois grupos étnicos o mesmo não ocorre. Segundo os autores, por pertencerem a igrejas nas quais a estrutura interna nutre oportunidades para exercer habilidades politicamente relevantes, e por pertencerem a igrejas mais politizadas em que são expostos a estímulos, pedidos de participaçáo e mensagens do púlpito acerca de assuntos políticos, os afro-americanos apresentam uma maior diferença que os latinos e os 
brancos no tocante ao recrutamento político (VERBA, SCHLOZMAN e BRADY, 1995).

Paul Djupe e Tobin Grant (2001), a respeito do papel das instituiçóes religiosas no desenvolvimento das habilidades cívicas e no recrutamento para o engajamento cívico, dedicam-se a analisar as formas como as instituiçóes religiosas promovem a participação política nos Estados Unidos. Segundo esses pesquisadores, a religião e as igrejas têm mostrado um grande potencial para afetar a política americana. Diante disso, buscam em Religious Institutions and Political Participation in America (2001) avaliar diretamente os papéis que a religiáo pode desempenhar na promoção da participação política para além do voto. Utilizando a mesma base de dados usada por Verba, Schlozman e Brady (1995) - Citizen Participation Study - e entendendo participação como comparecimento às urnas, trabalho de campanha, contato com autoridades governamentais, participação em protestos e em políticas comunitárias, os autores vão testar as sete hipóteses seguintes:

H1: Parishioners who are active in their churches will have a greater probability of participating in politics because of civic skill advantages.

H2: Parishioners who are recruited to politics by coreligionists will have a greater probability of participating in politics.

H3: Those with a clearer perception of the political orientations of the church will be more likely to participate in politics.

H4: Clergy-sponsored political meetings in church will increase the probability of a member participating in politics.

$\mathrm{H} 5$ : Valuing religious activities more than political activities will decrease the probability of a person participating in politics.

H6: Viewing church activity as a way to have a political impact will increase the probability of participating in politics.

H7: Members of different religious traditions will differ in their probabilities of participating in politics (DJUPE e GRANT, 2001, p. 305-308).

Inicialmente, concordam com as evidências que atestam o papel fundamental dos recursos seculares na explicação da participação, porém também afirmam que os indivíduos religiosos náo são politicamente ativos unicamente devido a tais recursos. Isso fica claro nos resultados que encontram, já que das sete hipóteses testadas, apenas duas (H1 e H7) não se mostraram válidas. As instituições religiosas, desta forma, interferem na participação política de cinco formas: 1) os paroquianos que são recrutados para a política por correligionários têm maior probabilidade de participar; 2) aqueles com uma percepção clara das orientaçóes políticas da igreja são mais 
propensos à ação política; 3) reuniôes políticas patrocinadas pelo clero na igreja aumentam a possibilidade dos membros serem ativos politicamente; 4) dar mais valor às atividades religiosas do que às atividades políticas diminui a probabilidade de uma pessoa participar politicamente; e 5) a visualização da atividade da igreja como uma forma de impacto político aumenta a probabilidade de participação (DJUPE e GRANT, 2001).

David E. Campbell, em Acts of faith: Churches and political engagement (2004), também parte de uma premissa semelhante à de Verba, Schlozman e Brady para pensar a relação entre participaçáo política e religião, porém seu foco de pesquisa são os evangélicos protestantes brancos. Entendendo participação política tanto como comparecimento às urnas como participação não eleitoral, o autor busca verificar como o tempo gasto pelos evangélicos dos Estados Unidos em prol de suas igrejas prejudica a participaçáo na comunidade maior e o engajamento político. Para Campbell, a igreja exige tanto tempo e energia de seus membros em suas atividades que sua participação em comunidades maiores e o seu engajamento político são prejudicados.

Porém, esse alto comprometimento de tempo que algumas igrejas pedem de seus membros não é o único foco do autor. Esse ainda busca entender como a rede social resultante da atividade religiosa contribui para uma ação política esporádica de seus membros. Uma vez que a participaçáo em atividades da igreja reforça os contatos sociais, esses contatos poderiam ser utilizados esporadicamente para uma rápida e intensa mobilização. Segundo o autor, pode-se esperar dos evangélicos, então, uma atitude política quando seus valores morais forem ameaçados (CAMPBELL, 2004).

Já Michael Jones-Correa e David L. Leal, em Political Participation: Does Religion Matter? (2001) testam as hipóteses de Verba, Schlozman e Brady (1995) a respeito da relação entre religião e participação política entre os latinos americanos católicos. Os pesquisadores buscam verificar se o argumento utilizado em Voice and Equality a respeito do baixo desenvolvimento de habilidades políticas de católicos se aplica a todos os membros desse segmento religioso, independentemente da etnia, bem como procuram identificar se essa teoria faz uma diferenciação satisfatória entre católicos e protestantes dentro do mesmo grupo étnico.

Para tanto utilizam os dados do Latino National Political Survey (LNPS) dos anos 1989/1990, um survey cuja amostragem traz os três maiores grupos étnicos latinos na América: americanos mexicanos, cubanos e porto-riquenhos. Ao selecionarem variáveis eleitorais e não eleitorais desse banco de dados, os autores não encontraram evidências que apoiem a hipótese de que os católicos dos grupos latinos 
abordados no LNPS são menos suscetíveis a serem ativos politicamente que os protestantes latinos. Assim, contrariando Verba, Schlozman e Brady (1995), os dados encontrados por Jones-Correa e Leal indicam que o catolicismo entre esses latinos não está associado com níveis reduzidos de participação, isto é, igrejas, tanto católicas quanto protestantes, oferecem um significativo encorajamento para o engajamento político.

Robert Putnam (1993 e 2000) também teoriza a respeito da importância das instituiçóes religiosas no desenvolvimento de habilidades cívicas, mas diferentemente de Verba, Schlozman e Brady (1995), o autor defende a relevância dessas instituiçôes para a formaçáo do capital social, entendido como o conjunto das conexóes entre indivíduos por meio das quais as redes sociais e as normas de reciprocidade e confiança surgem. Destaca, então, a importância dos laços sociais e normas compartilhadas para o bem-estar social e para a eficiência econômica, por meio dos quais a sociedade civil promove diretamente capital social, que em troca facilita a participação política e o bom governo.

Putnam (2000) enfatiza a importância das igrejas e outras organizaçóes religiosas na formação desse capital social, afirmando que as igrejas protestantes americanas têm sido através dos séculos, instituiçôes sociais que têm promovido as bases organizacionais e psicológicas para uma variedade de movimentos sociais e políticos. Assim, as organizaçôes baseadas na fé têm servido à vida civil não apenas promovendo suporte social para seus membros e serviços sociais para a comunidade maior, mas também inculcando valores morais, encorajando o altruísmo e fomentando o recrutamento cívico. Um exemplo disso seria a importância da igreja protestante nas comunidades afro-americanas. Segundo o autor, ao encorajar a mistura de assuntos religiosos e comunitários, a tradição religiosa negra nos Estados Unidos faz com que as organizaçóes baseadas na fé sejam centrais ao capital social e ao engajamento cívico nessas comunidades (PUTNAM, 2000).

Com base nessas pesquisas já é possível acompanhar os caminhos que estão sendo traçados pelos estudos recentes a respeito da relação entre organizaçóes religiosas e comportamento político. Nota-se que a literatura não é consensual a respeito dessa relação e seus efeitos. Enquanto autores como Verba, Schlozman e Brady (1995) apontam essas instituiçóes no desenvolvimento de habilidades cívicas e no aumento das taxas de participação, Paul A. Djupe e J. Tobin Grant (2001) defendem que, apesar da frequência à igreja estar relacionada com o comportamento político dos indivíduos, as habilidades cívicas adquiridas nessa instituição não 
potencializam o engajamento político. Putnam (1993 e 2000), por sua vez, destaca a importância das instituiçóes religiosas no desenvolvimento de habilidades cívicas por uma perspectiva diferente desses autores, focando na formaçáo do capital social.

\section{Questões metodológicas}

A pesquisa, cujos resultados são apresentados no presente artigo, teve o seguinte problema central: existe uma relação significativa entre a participação em instituiçóes e organizaçóes religiosas e o comportamento político dos indivíduos brasileiros? Para responder a essa pergunta fundamental testamos a hipótese de que entre os religiosos o ativismo religioso, ou o status de praticante, eleva o envolvimento em modalidades tradicionais de participação política, mas não interfere no envolvimento em modalidades não tradicionais ou contestatórias de participação.

Essa afirmação provisória é derivada do estudo já citado de Verba, Schlozman e Brady (1995), que afirma a relevância das instituiçóes religiosas sobre o desenvolvimento de habilidades cívicas dos seus membros. Além disso, essas instituiçóes funcionariam como lugar de recrutamento e estímulo para o engajamento político, já que além de permitirem uma rede de contato por meio da qual os indivíduos são recrutados à participação, ainda permitem aos seus fiéis a exposição a conversas e mensagens políticas. Diante disso, detalhando nossa hipótese, nossa expectativa era de que as instituiçóes religiosas brasileiras contribuíssem para a participação política dos indivíduos e que, devido aos seus valores e princípios morais e éticos tradicionais, tal influência se manifestaria nas modalidades tradicionais ou convencionais e náo nas ligadas ao protesto político.

Para a condução dos testes a base empírica selecionada foi o Latin American Public Project - American Barometer ${ }^{1}$. No Brasil, até o momento em que as análises foram efetuadas, a última aplicação de questionários havia sido realizada entre 01 de março a 18 de abril de 2012 e contou com a supervisão de pesquisadores da Universidade de Brasília. De acordo com as notas técnicas do LAPOP, foram realizadas no país 1500 entrevistas. Para a construção de tal amostra, o projeto utilizou um desenho probabilístico nacional considerando os adultos em idade de voto e a margem de erro estimada para o inquérito foi de \pm 2.5 . A amostra é composta por cinco camadas que representam as cinco regióes geográficas principais:

\footnotetext{
${ }^{1}$ Conduzido pela Universidade de Vanderbilt, esse survey é rodado a cada dois anos, abrangendo atualmente 26 países, incluindo todos da América do Sul, do Norte, Central e o Caribe. Ao buscar medir valores e comportamentos democráticos, esse projeto utiliza-se de uma metodologia rigorosa, empregando cuidadosamente amostras nacionais estratificadas e agrupadas.
} 
Norte (216), Nordeste (336), Centro-oeste (217), Sudeste (479) e Sul (252). Cada estrato foi ainda sub estratificado por tamanho de município e por áreas urbanas e rurais, compondo 125 unidades amostrais finais, nas quais um total de 1.296 indivíduos foi entrevistado em áreas urbanas e 204 em zonas rurais.

Uma vez que nosso objetivo fundamental é analisar a relação entre ativismo religioso e participação política, tratamos a religião em todas as análises como uma variável independente, pois é ela que supostamente causa efeito na dependente (participação). Assim, já que o número de variáveis analisadas é bastante amplo, tanto no campo das denominações religiosas quanto das modalidades de participação política, escolhemos as variáveis que consideramos prioritárias.

Para mensurar a influência das instituiçóes religiosas no comportamento político dos brasileiros, inserimos nas análises uma medida acerca do ativismo religioso dos indivíduos, obtido com a interrogação Com que frequência o(a) Sr./Sra. vai à missa ou culto religioso? Essa variável foi recodificada de duas formas diferentes, a primeira considerando como um indivíduo ativo religiosamente aquele que frequenta um culto religioso "mais de uma vez por semana" ou "uma vez por semana" e os não ativos o restante dos respondentes. A segunda recodificação foi feita de forma a separar os ativos e os não ativos dos principais segmentos religiosos brasileiros, isto é, católico, protestante tradicional ou evangélico não pentecostal, evangélico pentecostal e religiôes tradicionais ou nativas (Candomblé, Umbanda, Voodoo, Rastafari, religióes Mayas, Santo Daime, Esotérica). A ideia aqui foi verificar o impacto da filiação religiosa, mas também da vinculação mais ativa a uma determinada religião no padrão de atuação política dos cidadãos.

Adicionalmente, inserimos uma variável a respeito da participação em organizaçôes religiosas - Por favor, diga se o (a) Sr./Sra. assiste às reuniôes de alguma organizaçáo religiosa? - recodificada de forma a separar os que participam "pelo menos uma vez por semana" e "uma ou duas vezes ao mês" daqueles que náo participam (assistem às reuniôes "uma ou duas vezes ao ano", ou "nunca"). A segunda recodificação foi feita também de forma a separar os ativos e os inativos de cada segmento religioso.

No terreno da participaçáo, procuramos selecionar variáveis que dizem respeito a uma ampla variedade de modalidades de envolvimento convencional ${ }^{2} \mathrm{e}$

${ }^{2}$ Utilizamos a tipologia de classificação de participação política proposta por Ronald Inglehart e colaboradores (INGLEHART e CATTERBERG, 2002; INGLEHART e WELZEL, 2009). Os autores diferenciam as modalidades de participação de acordo com sua relação com as elites da 
náo-convencional. $\mathrm{O}$ mesmo processo de recodificação foi repetido com as variáveis de participaçáo política. Dentre as modalidades convencionais selecionamos as variáveis geradas pelas perguntas: $O(A)$ Sr./Sra. votou nas últimas eleiçôes presidenciais de 2010?; O(A) Sr./Sra. assistiu a alguma audiência pública na Câmara dos Vereadores nos últimos doze meses?; Por favor, diga se o (a) Sr./Sra. assiste às reuniōes de uma associação de bairro ou junta de melhorias para a comunidade?; Por favor, diga se o (a) Sr./Sra. assiste às reunióes de um partido ou movimento politico? A primeira dessas variáveis ficou dicotomizada apenas em "sim" e "não", enquanto que nas demais combinamos de um lado as respostas "uma vez por semana" e "uma ou duas vezes ao mês" e, de outro, as alternativas "uma ou duas vezes ao ano" e "nunca".

As variáveis utilizadas para mensurar a participação política não convencional são derivadas das perguntas: Nos últimos doze meses, o(a) Sr./Sra., participou de alguma manifestação ou protesto público?; E no último ano, o(a) Sr./Sra. participou em algum bloqueio de alguma rua ou espaço público como forma de protesto?; Nos últimos doze meses o(a) Sr./Sra assinou alguma petição (abaixo-assinado)?; Nos últimos doze meses o(a) Sr./Sra. deixou de comprar algum produto, alimento ou qualquer outra coisa por motivos políticos? Ao recodificarmos essas variáveis combinamos de um lado a resposta "sim" e, de outro, a alternativa "não".

Para produzir, a partir desses dados amostrais, afirmaçóes que sejam válidas para a população brasileira, empregamos o aparato técnico envolvido nos testes de significância estatística. Para saber se de fato as variáveis que cruzamos estão relacionadas ao ponto de podermos realizar a inferência desejada utilizamos o teste Qui-Quadrado ( $\chi 2)$. Os resultados desses testes, porém, não podem ser tomados como definitivos sobre o relacionamento entre as variáveis, já que não possibilitam a utilização de controles relevantes, como aqueles advindos de variáveis sócio demográficas dos componentes da amostra (BOHRNSTEDT e KNOKE, 1988). Assim, depois de observadas essas primeiras associaçôes, foram utilizados nas associaçóes significativas modelos multivariados com a inserção dos atributos sexo, idade e escolaridade. O modelo escolhido foi o de regressão logística ou binária,

sociedade. Essas modalidades são divididas em açôes elite directed, isto é, a participação dos cidadãos por meio de organizaçóes hierárquicas, tais como partidos e sindicatos, e açóes elite challenging, marcadas pela ação direta sem a intermediação de representantes, não institucionalizada, como os protestos, boicotes, abaixo-assinados e manifestaçôes. Para uma discussão detalhada sobre o debate classificatório entre modalidades tradicionais (ou convencionais) e formas contestatórias (ou de protesto) consultar o livro Participação Política na América Latina, de Ribeiro e Borba (2015). 
técnica que nos permitiu calcular as razóes de possibilidade de o ativismo religioso influenciar no comportamento político dos indivíduos (POWERS e XIE, 2008).

\section{Instituições religiosas e participação politica}

Iniciando pelas análises bivariadas, podemos ver abaixo (Tabela 1) que os cruzamentos resultantes entre frequentar cultos e missas e as modalidades de participação políticas convencionais não demonstram associação com a participação eleitoral para nenhum grupo religioso. Tal resultado nos chamou a atenção, uma vez que a religião tem se feito notar no momento eleitoral desde a eleiçáo de 1986 para o Congresso Constituinte. Contudo, segundo Oro e Mariano, foi na eleição de 2010 que "a influência e o poder dos dirigentes, grupos e movimentos católicos e pentecostais sobre os principais candidatos atingiram o ápice" (ORO e MARIANO, 2010 , p. 22). Se a presença religiosa nas eleiçóes presidenciais desse ano foi táo explícita ao ponto de não poder ser ignorada por diversos pesquisadores brasileiros (ORO e MARIANO, 2010; BEM e LEISTNER, 2010; PIERUCCI, 2011), como explicar a ausência estatística de ligação entre os praticantes religiosos, em especial católicos e evangélicos, com a participação eleitoral?

Tabela 1 - Participação Política Convencional e Frequência a Cultos e Missas

\begin{tabular}{l|l|l|l|l|l|l|l|l}
\hline \multirow{2}{*}{ Variáveis } & \multicolumn{2}{l|}{$\begin{array}{l}\text { Participaçáo } \\
\text { Eleitoral }\end{array}$} & \multicolumn{2}{l|}{$\begin{array}{l}\text { Audiência } \\
\text { Pública }\end{array}$} & \multicolumn{2}{l}{$\begin{array}{l}\text { Associaçáo de } \\
\text { Bairro }\end{array}$} & \multicolumn{2}{l}{$\begin{array}{l}\text { Partido ou } \\
\text { Movimento } \\
\text { Político }\end{array}$} \\
\cline { 2 - 11 } & $\boldsymbol{X}^{\mathbf{2}}$ & Sig. & $\boldsymbol{X}^{\mathbf{2}}$ & Sig. & $\boldsymbol{X}^{\mathbf{2}}$ & Sig. & $\boldsymbol{X}^{\mathbf{2}}$ & Sig. \\
\hline Católico & 5,698 &, 058 & 2,110 &, 348 & 6,621 &, 037 &, 884 &, 643 \\
\hline Protestante Tradicional & 2,372 &, 305 & 4,007 &, 135 & 3,227 &, 199 &, 714 &, 700 \\
\hline Evangélica Pentecostal & 4,747 &, 093 & 11,761 &, 003 & 5,696 &, 058 & 3,228 &, 199 \\
\hline Religiónes Nativas & 5,396 &, 067 & 23,075 &, 000 & 5,108 &, 078 & 13,832 &, 001 \\
\hline
\end{tabular}

Fonte: Projeto de Opinião Pública da América Latina (LAPOP, 2012).

A única explicaçáo que nossa base de dados nos permite oferecer, neste momento, relaciona-se com a obrigatoriedade do voto no Brasil. De acordo com a Constituição Federal, o voto é facultativo para os analfabetos, para quem tem 16 e 17 anos e para maiores de 70 anos, já para os maiores de 18 anos e menores de 70 anos o voto é obrigatório. Haja vista que a construção da amostra do LAPOP utiliza um desenho probabilístico nacional que considera os adultos em idade de voto, e o voto é um poder-dever brasileiro, não é possível separar na amostra os indivíduos que 
participam do momento eleitoral como uma forma de engajamento político daqueles que comparecem à urna apenas para cumprimento de uma obrigação cívica.

Tal resultado não chega a colocar em cheque nossa hipótese, haja vista que essa modalidade de participaçáo foi a única dentre as formas de participação burocratizadas e convencionais aqui abordadas a não apresentar resultado com valor estatístico significativo. Assim, ser ativo religiosamente está associado com participação em audiência pública na Câmara dos Vereadores - evangélicos pentecostais $(, 003)$ e religióes nativas $(, 000)$-, com participação em associaçôes de bairro e juntas de melhoria - católico $(, 037)$ - e com participação em reuniōes de partido ou movimento político - religióes nativas $(, 001)$.

Além da variável de frequência a cultos e às missas, utilizamos para verificar o papel das instituiçóes religiosas no comportamento político dos indivíduos a participação em organizaçóes religiosas. Quando olhamos para os cruzamentos resultantes entre essa variável e as modalidades de participação políticas convencionais (Tabela 2) encontramos a primeira e única associação estatisticamente significativa com participação eleitoral, que ocorre entre os evangélicos pentecostais $(, 048)$.

Tabela 2 - Participação Política Convencional e Organizações Religiosas

\begin{tabular}{l|l|l|l|l|l|l|l|l}
\hline \multirow{2}{*}{ Variáveis } & \multicolumn{2}{l}{$\begin{array}{l}\text { Participaçáo } \\
\text { Eleitoral }\end{array}$} & \multicolumn{2}{l}{$\begin{array}{l}\text { Audiência } \\
\text { Pública }\end{array}$} & \multicolumn{2}{l}{$\begin{array}{l}\text { Associaçáo de } \\
\text { Bairro }\end{array}$} & \multicolumn{2}{l}{$\begin{array}{l}\text { Partido ou } \\
\text { Movimento } \\
\text { Político }\end{array}$} \\
\cline { 2 - 10 } & $X^{\mathbf{2}}$ & Sig. & $\boldsymbol{X}^{\mathbf{2}}$ & Sig. & $\boldsymbol{X}^{\mathbf{2}}$ & Sig. & $\boldsymbol{X}^{\mathbf{2}}$ & Sig. \\
\hline Católico & 5,475 &, 065 & 6,461 &, 040 & 10,910 &, 004 & 1,005 &, 605 \\
\hline Protestante Tradicional & 1,794 &, 408 & 2,157 &, 340 & 10,776 &, 005 &, 455 &, 796 \\
\hline Evangélica Pentecostal & 6,086 &, 048 & 9,541 &, 008 & 14,359 &, 001 & 5,216 &, 074 \\
\hline Religióes Nativas & 5,895 &, 052 & 11,244 &, 004 & 19,469 &, 000 & 4,477 &, 107 \\
\hline
\end{tabular}

Fonte: Projeto de Opinião Pública da América Latina (LAPOP, 2012).

Quanto à participação em audiência pública, temos associaçóes estatisticamente significativas com os católicos $(, 040)$, evangélicos pentecostais $(, 008)$ e religióes nativas (,004). Para a participação em associaçôes de bairro e juntas de melhorias, os dados apresentam significância para todos os grupos religiosos católico (,004), protestante tradicional (,005), evangélico pentecostal (,001) e religióes nativas $(, 000)$. Já a participação em partido ou movimento não apresentou nenhuma associação entre os indivíduos que participam em organizaçóes religiosas.

Como explicar essa ligação entre a participação em instituiçóes religiosas e o comportamento político? Segundo Verba, Schlozman e Brady (1995), o 
envolvimento dos indivíduos em instituiçôes religiosas pode aumentar o seu potencial para a atividade política de duas formas: primeiro, gerando oportunidades para a prática de habilidades cívicas; segundo, por meio do recrutamento e da exposição a estímulos políticos.

Segundo os autores, as igrejas promovem a chance de seus membros desenvolverem e praticarem habilidades cívicas, isto é, essas instituiçôes oferecem oportunidade de adquirir habilidades organizacionais e de comunicação em contextos que não estão diretamente relacionados com a política. Tais habilidades permitem que seus membros vejam a atividade política de forma menos assustadora, tendo mais probabilidade de tomarem parte dela. Assim, as instituiçóes religiosas favorecem de diferentes formas o incremento da atividade do cidadão na política, contribuindo para o seu aprendizado de como ser um cidadáo ativo (VERBA, SCHLOZMAN e BRADY, 1995).

Contudo, essas instituiçôes não contribuem apenas para o desenvolvimento das habilidades cívicas, elas também funcionam como um local de recrutamento e estímulo de engajamento político. Devido à rede de contatos construída nas igrejas e nas organizações religiosas, essas instituições permitem que os indivíduos sejam recrutados para a participação e convidados a se envolverem na ação política. Mas tal recrutamento não se dá apenas por meio das redes de contato, pois não raras vezes as próprias instituiçôes geram pedidos de participação (VERBA, SCHLOZMAN e BRADY, 1995).

Não é incomum dentro das instituiçôes religiosas que a liderança convide seus membros a votar em um candidato particular ou a tomar uma determinada açáo política. Tais palpites e discussôes de assuntos políticos no púlpito fazem com que os seus membros sejam expostos a mensagens, tópicos e discussóes políticas. Isso, segundo os autores, interfere e contribui para a participação dos indivíduos, aumentando suas chances de ação política.

Os argumentos de Robert Putnam (1993 e 2000) reiteram a importância da igreja e das instituiçôes religiosas no desenvolvimento de habilidades cívicas. Ao defender a relevância dessas instituições para a formação do capital social, que facilita a participação política, o autor afirma que as igrejas americanas têm funcionado como instituiçóes sociais, promovendo as bases organizacionais e psicológicas para movimentos sociais e políticos, mas náo apenas isso, têm inculcado valores morais, encorajado o altruísmo e fomentado o recrutamento cívico. 
Dando continuidade às análises, acrescentamos as variáveis de controle sexo, idade e escolaridade e os resultados continuam consistentes e favoráveis à hipótese do efeito da religiáo sobre o ativismo. Os coeficientes e exponenciais dispostos na Tabela 3 (abaixo) indicam que ser ativo religiosamente aumenta em 69,5\% as chances de um evangélico pentecostal participar de audiência pública na Câmara dos Vereadores. Frequentar a cultos e missas aumenta, ainda, em 100,2\% as chances de um indivíduo das religióes nativas participarem dessa modalidade e em $74,9 \%$ a probabilidade de participarem de reunióes de partido ou movimentos políticos.

Tabela 3 - Regressão Logística para Participação Convencional por Frequência a Cultos e Missas

\begin{tabular}{c|c|c|c|c|c|c}
\hline \multirow{2}{*}{ Variáveis } & \multicolumn{3}{|c|}{ Audiência Pública } & \multicolumn{2}{c|}{ Associaçáo de Bairro } & \multicolumn{2}{c}{$\begin{array}{c}\text { Partido ou } \\
\text { Movimento } \\
\text { Político }\end{array}$} \\
\cline { 2 - 7 } & Sig & Exp (B) & Sig & Expo (B) & Sig & Expo (B) \\
\hline Católico & - & - &, 250 & 1,219 & - & - \\
\hline Evangélica Pentecostal &, 001 & 1,695 & - & - & - & - \\
\hline Religióes Nativas &, 001 & 2,002 & - & - &, 000 & 1,749 \\
\hline
\end{tabular}

Fonte: Projeto de Opinião Pública da América Latina (LAPOP, 2012).

Já no caso da participação em associação de bairros e juntas de melhorias, apesar do teste Qui-quadrado mostrar a existência de uma relação entre os católicos "praticantes" com essa modalidade de participação, quando inseridas as variáveis de controle sociodemográficas a religiáo deixa de ser um preditor significativo.

Tabela 4 - Regressão Logística para Participação Convencional por Organizaçóes Religiosas

\begin{tabular}{l|l|c|l|c|l|c}
\hline \multirow{2}{*}{ Variáveis } & \multicolumn{2}{|l|}{ Participaçáo Eleitoral } & \multicolumn{2}{c|}{ Audiência Pública } & \multicolumn{2}{l}{ Associaçáo de Bairro } \\
\cline { 2 - 7 } & Sig & Exp (B) & Sig & Exp (B) & Sig & Expo (B) \\
\hline Católico & - & - &, 208 &, 813 &, 023 & 1,450 \\
\hline Protestante Tradicional & - & - & - & - &, 004 & 1,557 \\
\hline Evangélica Pentecostal &, 316 & 1,149 & - & 1,602 & - & 1,575 \\
\hline Religióes Nativas & - & - &, 006 & 1,728 &, 003 & 1,800 \\
\hline
\end{tabular}

Fonte: Projeto de Opiniáo Pública da América Latina (LAPOP, 2012).

O mesmo ocorre com algumas associaçóes encontradas na participação em organizaçóes religiosas. Após acrescentarmos as variáveis de controle sexo, idade e educação, não tivemos a confirmação da associação no caso da participação eleitoral 
entre os evangélicos e do envolvimento em audiência pública na Câmara dos Vereadores entre os católicos (Tabela 4).

Isso, contudo, não diminui a relevância das organizaçóes religiosas, já que os resultados também revelam que participar nessas organizaçôes aumenta em $60,2 \%$ as chances de um evangélico pentecostal participar em audiência pública e em 57,5\% a sua probabilidade de participar em uma associação de bairro ou junta de melhorias. A única relação que encontramos, entre os protestantes tradicionais e a participação política, ocorre no meio dos religiosos que participam regularmente de organizaçóes religiosas. Participar nessas instituiçôes aumenta em 55,7\% a chance de um protestante participar em associaçóes de bairro e juntas de melhorias.

Encontramos, ainda, que participar em organizaçóes religiosas aumenta em $45 \%$ a probabilidade de um católico participar de associaçôes de bairro, já entre as religióes nativas a probabilidade de participar dessa modalidade de ação política elevase para $80 \%$. Por fim, ser ativo religiosamente aumenta em $72,8 \%$ as chances de um indivíduo pertencente às religióes nativas participarem de uma audiência pública.

Apesar da ligação entre instituição religiosa e participação eleitoral não ter se confirmado, os dados nos permitem afirmar que no Brasil, assim como nos Estados Unidos, o envolvimento dos indivíduos em instituiçóes dessa natureza contribui para o aumento de seu potencial para a atividade política, seja por meio do desenvolvimento de habilidades cívicas ou pela exposição a mensagens e discussóes políticas. Mas não apenas isso, os resultados confirmam a nossa hipótese de que, entre os religiosos, o ativismo religioso ou o status de praticante eleva o envolvimento em modalidades convencionais e burocratizadas de participação política, comandadas ou direcionadas pela elite. Tendo constatado isso, nosso próximo passo é verificar como esse ativismo religioso relaciona-se com as modalidades náo convencionais de participação política.

$\mathrm{Na}$ tabela abaixo (Tabela 5) podemos ver que na participação em manifestaçáo ou protesto público temos números estatisticamente significativos apenas entre os católicos praticantes (,011). Já assinatura de petição (,037) e participação em boicote $(, 014)$ associam-se com os indivíduos das religióes nativas que frequentam a cultos e missas regularmente. A única das modalidades a não apresentar relação estatisticamente significativa com o ativismo religioso foi a participação em bloqueio de rua ou espaço público. Dentre os grupos religiosos, nem os protestantes tradicionais, nem os evangélicos pentecostais mostraram ligação com as formas de ação política não institucionalizada ou de oposição às elites. 
Tabela 5 - Participação Política Não Convencional e Frequência a Cultos e Missas

\begin{tabular}{l|l|l|l|l|l|l|l|l}
\hline \multirow{2}{*}{ Variáveis } & \multicolumn{2}{|c|}{$\begin{array}{c}\text { Manifestaçáo } \\
\text { ou Protesto } \\
\text { Público }\end{array}$} & \multicolumn{2}{|c|}{$\begin{array}{c}\text { Bloqueio de } \\
\text { Rua ou Espaço } \\
\text { Público }\end{array}$} & \multicolumn{2}{c|}{$\begin{array}{c}\text { Assinatura de } \\
\text { Petiçáo }\end{array}$} & \multicolumn{2}{|c}{ Boicote } \\
\cline { 2 - 10 } & $X^{\mathbf{2}}$ & Sig. & $X^{\mathbf{2}}$ & Sig. & $X^{\mathbf{2}}$ & Sig. & $X^{\mathbf{2}}$ & Sig. \\
\hline Católico & 9,089 &, 011 &, 310 &, 856 &, 868 &, 648 & 1,876 &, 391 \\
\hline Protestante Tradicional & 5,907 &, 052 & 1,803 &, 406 & 2,857 &, 240 & 1,463 &, 481 \\
\hline Evangélica Pentecostal & 1,509 &, 470 &, 127 &, 721 & 1,239 &, 538 & 1,221 &, 543 \\
\hline Religióes Nativas & 3,092 &, 213 & 2,859 &, 239 & 6,616 &, 037 & 8,485 &, 014 \\
\hline
\end{tabular}

Fonte: Projeto de Opinião Pública da América Latina (LAPOP, 2012).

Assim como frequentar a cultos e missas, participar em organizaçóes religiosas também está associado com as modalidades não convencionais aqui tratadas. Como podemos ver abaixo, enquanto os católicos que participam dessas organizaçóes estão associados com as participaçóes em manifestação ou protesto público $(, 000)$ e em bloqueio de rua ou espaço público (,030), os indivíduos das religióes nativas apresentam valores significativos para a assinatura de petição $(, 013)$ e boicote $(, 020)$.

Tabela 6 - Participação Política Não Convencional e Organizaçôes Religiosas

\begin{tabular}{l|l|l|l|l|l|l|l|l}
\hline \multirow{2}{*}{ Variáveis } & \multicolumn{1}{|c|}{$\begin{array}{c}\text { Manifestaçáo } \\
\text { ou Protesto } \\
\text { Público }\end{array}$} & \multicolumn{2}{|c|}{$\begin{array}{c}\text { Bloqueio de } \\
\text { Rua ou Espaço } \\
\text { Público }\end{array}$} & \multicolumn{2}{|c|}{$\begin{array}{c}\text { Assinatura de } \\
\text { Petiçáo }\end{array}$} & \multicolumn{2}{|c}{ Boicote } \\
\cline { 2 - 10 } & $X^{\mathbf{2}}$ & Sig. & $X^{\mathbf{2}}$ & Sig. & $X^{\mathbf{2}}$ & Sig. & $X^{\mathbf{2}}$ & Sig. \\
\hline Católico & 15,777 &, 000 & 7,036 &, 030 &, 629 &, 730 &, 386 &, 824 \\
\hline Protestante Tradicional & 3,121 &, 210 & 3,912 &, 141 & 3,746 &, 154 & 2,232 &, 328 \\
\hline Evangélica Pentecostal & 1,120 &, 571 & 1,961 &, 375 & 2,820 &, 244 & 2,333 &, 312 \\
\hline Religiónes Nativas & 1,612 &, 447 & 5,895 &, 052 & 8,658 &, 013 & 7,855 &, 020 \\
\hline
\end{tabular}

Fonte: Projeto de Opinião Pública da América Latina (LAPOP, 2012).

Do que foi apresentado até o momento, podemos notar que ao limitarmos o alcance da nossa hipótese às modalidades convencionais, estamos deixando de fora um importante aspecto da relaçáo entre o ativismo religioso ou o status de participante e o comportamento político dos brasileiros. Os dados apontam que o poder das instituiçôes religiosas brasileiras em fomentar a atividade do cidadáo na política parece maior do que o esperado.

Quando controlada pelas variáveis sexo, idade e educação (Tabela 7), a característica preditora do ativismo religioso só se mantém entre os indivíduos das religióes nativas que frequentam regularmente a cultos e missas, e apenas para a 
participação em assinatura de petição (45,9\%). Para as demais variáveis as associações não se confirmam, o que significa que nesses casos o status de praticante religioso não funciona como preditor ou como explicação para a ação política de participar em manifestação ou protesto público e de deixar de comprar algum produto, alimento ou qualquer outra coisa por motivos políticos.

Tabela 7 - Regressão Logística para Participação Não Convencional por Frequência a Cultos e Missas

\begin{tabular}{|c|c|c|c|c|c|c|c|c|}
\hline \multirow[t]{2}{*}{ Variáveis } & \multicolumn{2}{|c|}{$\begin{array}{l}\text { Manifestaçáo } \\
\text { ou Protesto } \\
\text { Público }\end{array}$} & \multicolumn{2}{|c|}{$\begin{array}{l}\text { Bloqueio de Rua } \\
\text { ou } \\
\text { Público }\end{array}$} & \multicolumn{2}{|c|}{$\begin{array}{l}\text { Assinatura de } \\
\text { Petiçáo }\end{array}$} & \multicolumn{2}{|c|}{ Boicote } \\
\hline & $X^{2}$ Sig & $\begin{array}{l}\operatorname{Exp} \\
\text { (B) }\end{array}$ & $X^{2}$ Sig & $\begin{array}{l}\operatorname{Exp} \\
\text { (B) }\end{array}$ & $X^{2}$ Sig & $\begin{array}{l}\text { Expo } \\
\text { (B) }\end{array}$ & $X^{2}$ Sig & $\begin{array}{l}\text { Expo } \\
\text { (B) }\end{array}$ \\
\hline Católico & ,011 & ,729 & ,856 & - & ,648 & - & ,391 & - \\
\hline $\begin{array}{l}\text { Protestante } \\
\text { Tradicional }\end{array}$ &, 052 & - & ,406 & - & 240 & - & ,481 & - \\
\hline Evangélica Pentecostal & ,470 & - & ,721 & - & ,538 & - &, 543 & - \\
\hline Religióes Nativas & ,213 & - & ,239 & - & 037 & 1,459 & ,014 & 2,124 \\
\hline
\end{tabular}

Fonte: Projeto de Opiniāo Pública da América Latina (LAPOP, 2012).

No caso da participação em organizações religiosas isso só ocorre com bloqueio de rua ou espaço público, nas demais modalidades a regressão logística binária demonstra que o ativismo religioso serve como preditor da participaçáo política (Tabela 8). Nossos testes demonstram, então, que ser católico "praticante" diminui em 32,8\% a chance de um indivíduo participar de alguma manifestação ou protesto público. Já frequentar instituiçôes de religiōes nativas aumenta em 51,8\% a probabilidade de participação em abaixo-assinados e em 155,3\% de deixar de comprar algum produto, alimento ou qualquer outra coisa por motivos políticos.

Tabela 8 - Regressão Logística para Participação Não Convencional por Organizações Religiosas

\begin{tabular}{c|c|c|c|c|c|c|c|c}
\hline \multirow{2}{*}{ Variáveis } & \multicolumn{2}{|c|}{$\begin{array}{l}\text { Manifestaçáo ou } \\
\text { Protesto Público }\end{array}$} & $\begin{array}{c}\text { Bloqueio de Rua } \\
\text { ou Espaço } \\
\text { Público }\end{array}$ & \multicolumn{2}{c|}{$\begin{array}{c}\text { Assinatura de } \\
\text { Petiçáo }\end{array}$} & \multicolumn{2}{c}{ Boicote } \\
\cline { 2 - 9 } & $X^{2}$ Sig & Exp (B) & $X^{2}$ Sig & Exp (B) & $X^{2}$ Sig & Expo (B) & $X^{\mathbf{2}}$ Sig & Expo (B) \\
\hline Católico &, 039 &, 672 &, 357 &, 723 & - & - & - & - \\
\hline $\begin{array}{c}\text { Religióes } \\
\text { Nativas }\end{array}$ & - & - & - & - &, 002 & 1,518 &, 013 & 2,553 \\
\hline
\end{tabular}

Fonte: Projeto de Opinião Pública da América Latina (LAPOP, 2012). 
Ao observarmos os efeitos das instituiçóes religiosas, tanto nas modalidades de participação convencionais quanto nas não convencionais, notamos que o tipo de igreja e de organização religiosa que os indivíduos frequentam, importam para a participação política, já que alguns grupos religiosos mostraram associações com um número maior de modalidades do que outros. Segundo Verba, Schlozman e Brady (1995), isso ocorre porque diferentes igrejas promovem diferentes oportunidades de aquisição de habilidades cívicas e de contato com mensagens e discussôes políticas.

Os autores afirmam que, para a realidade americana, o exercício das habilidades cívicas desenvolvidas nas instituições religiosas está relacionado não apenas às características individuais como também às características das igrejas protestantes e católicas. Segundo esses, nos Estados Unidos as igrejas protestantes por tenderem a ser menores, por permitirem uma maior participação dos seus membros na liturgia e por serem predominantemente organizadas em bases congregacionais e não hierárquicas, propiciam a seus membros maiores oportunidades de exercer habilidades cívicas do que as igrejas católicas, o que contribui para uma maior ação política desse grupo. Esse argumento é criticado por Jones-Correa e Leal (2001) que afirmam que naquele país igrejas tanto católicas quanto protestantes oferecem um significativo encorajamento para o engajamento político.

No Brasil, as igrejas evangélicas são marcadas por uma imensa diversidade organizacional, teológica, litúrgica e política. Qualquer fiel pode fundar um novo templo, sem sair do mundo evangélico. As igrejas pentecostais se desenvolvem na tradição dos pregadores leigos, de crentes que se distinguem por sua devoção e seu fervor (FRESTON, 1993). Essas, assim como as americanas, permitem uma maior participação de seus membros na liturgia, possibilitando uma participação anárquica ou plural da palavra. Como aponta André Corten (1995, p. 62) "qualquer fiel pode pontuar o culto de um 'aleluia' ou de um 'glória a Deus' sonoro”.

O fato de nossos dados apontarem que frequentar a cultos ou organizaçóes evangélicas aumenta as chances de um indivíduo participar em audiência pública na Câmara dos Vereadores, e em associação de bairro ou junta de melhorias, nos faz pensar que essa interaçáo ocorrida durante os cultos pode estar servindo de oportunidade de desenvolvimento das habilidades cívicas necessárias para a ação política. Tal oportunidade, somada às mensagens e palpites políticos dos líderes desse segmento religioso, bem conhecidas das últimas campanhas eleitorais, têm influenciado a participação política tradicional dos evangélicos.

Cabe destacar que apesar das instituiçóes evangélicas terem o potencial de aumentar a atividade política dos brasileiros, isto não se dá da mesma forma que nos 
Estados Unidos. No Brasil, o peso histórico da presença evangélica em comparação com a católica é menor, uma vez que a nossa colonizaçáo foi marcada por um catolicismo missionário. Além disso, a perspectiva escatológica de espera do retorno de Cristo fez, durante muitos anos, com que os evangélicos brasileiros se auto excluíssem da política, considerando a participação política uma perda de tempo (CORTEN, 1995; FRESTON, 1993).

Dada a relação histórica existente entre a Igreja Católica e o Estado brasileiro, era de se esperar que essa instituição religiosa fosse a que mais contribuísse para o crescimento do engajamento político dos indivíduos. Isso, contudo, não ocorre. Apesar da participação em organizaçóes católicas aumentar o engajamento em associaçóes de bairros e juntas de melhorias, nossos dados demonstram que o ativismo católico também diminui a probabilidade de um indivíduo participar de alguma manifestação ou protesto público.

Uma explicação para esse fenômeno é a apresentada por Verba, Schlozman e Brady (1995), de que as igrejas católicas, por serem instituiçôes com uma hierarquia bem estabelecida e rígida, proporcionam poucas oportunidades de desenvolvimento de habilidades cívicas. Tal explicação, contudo, não dá conta de explicar satisfatoriamente a pequena influência da Igreja Católica no comportamento político dos brasileiros, pois apesar dos fiéis não terem uma grande abertura para participação durante as missas, esses têm a possibilidade de entrar em contato com assuntos e discussóes políticas nas Comunidades Eclesiásticas de Base e nas Pastorais, organizaçóes religiosas que ainda hoje têm como objetivo uma reflexão crítica a respeito da realidade e da sua relação com o Evangelho. Haja vista que a base de dados que utilizamos não apresenta informaçóes adicionais acerca dos diferentes segmentos e movimentos católicos, não é possível nos aprofundarmos nessa discussão.

As instituiçóes religiosas que apresentaram o maior número de associaçóes com a participação política, tanto convencional quanto não convencional, foram as das religiôes nativas. Nossos dados demonstram que frequentar cultos ou organizaçôes dessas religiōes aumentam a probabilidade dos indivíduos participarem em audiência pública, associaçóes de bairros, reuniôes de partido ou movimentos políticos e em boicotes.

Como explicarmos tamanho efeito? Essas instituiçôes parecem ter no Brasil uma significância semelhante à das igrejas protestantes negras nos Estados Unidos, em sua capacidade de desenvolvimento de habilidades e de fornecimento de uma infraestrutura organizacional para a ação política. Segundo Verba, Schlozman e Brady 
(1995), as congregaçóes religiosas tendem a ser relativamente homogêneas socialmente, pois aqueles que adoram juntos normalmente compartilham não apenas sua fé como também sua raça, etnia e classe social. Isso permite uma melhor distribuição de oportunidades de exercer habilidades cívicas, trazendo para a participação na vida política grupos em desvantagem e aqueles que de outro modo não podem ou não conseguem envolver-se na política.

Segundo Putnam (2000), ao encorajar a mistura de assuntos religiosos e comunitários a tradição religiosa negra nos Estados Unidos faz com que as organizaçôes baseadas na fé sejam centrais a mobilização dos indivíduos. Ao que parece, a mistura dos assuntos religiosos com os movimentos sociais negros tem feito no Brasil com que as organizaçóes baseadas nas religiôes nativas sejam centrais para o engajamento na vida política nacional.

\section{Considerações finais}

Ao nos dedicarmos ao estudo da relação entre ativismo religioso e participação política nos deparamos com alguns problemas. $\mathrm{O}$ primeiro diz respeito à dificuldade de se encontrar literatura brasileira que trate do comportamento político e sua relação com a religiáo, por isso tivemos que recorrer à literatura norte-americana que aborda essa temática. Como a realidade social americana difere da brasileira foi necessário adaptá-las para podermos aplicá-las ao nosso contexto.

A escassez de perguntas a respeito da religião nos surveys foi o segundo problema encontrado durante o desenrolar da pesquisa. Infelizmente, as questóes que dizem respeito às crenças e valores religiosos dos indivíduos ainda são precárias nos principais questionários de opiniáo pública aplicados no Brasil, o que limita muito o alcance da pesquisa acerca dessa temática e sua relação com a participação política.

Contudo, apesar das dificuldades, conseguimos encontrar circunstâncias diferentes das observadas em outros estudos e esperamos que os resultados deste artigo venham a contribuir para a compreensão da participação política em nosso contexto. Como apontado em vários momentos deste texto, a presença da religiáo na política nacional não é um fenômeno recente. Esse relacionamento tem se construído desde a colonização do nosso país e parece longe de acabar. A luta da Igreja Católica por manter sua hegemonia como religiáo dominante, a busca por legitimação e por reconhecimento das religiōes de matriz afro, a procura dos evangélicos em defender seus valores morais e éticos, e tantos outros aspectos da religiosidade brasileira, deixaram e deixam marcas na esfera pública que não podem ser ignoradas. 
Apesar do foco principal dos pesquisadores brasileiros ainda estar na inserção dos grupos religiosos, principalmente dos evangélicos, na política eleitoral e partidária, o conjunto dos resultados apresentados nesse artigo indica que, para realmente entendermos a influência e a presença da religiáo na política nacional, precisamos ampliar nossos horizontes para dimensões não eleitorais.

Ednaldo Aparecido Ribeiro é Doutor em Sociologia pela Universidade Federal do Paraná e Professor Adjunto de Ciência Politica na Universidade Estadual de Maringá. E-mail: ednaldoribeiro@icloud.com.

- Alice Vila Nova Procopiuk Walter é Mestre em Ciências Sociais pela Universidade Estadual de Maringá e Doutoranda do Programa de Pós-graduação em Ciência Política da Universidade Federal do Paraná. E-mail: alice14@gmail.com

\section{Referências}

BEM, Daniel F. de; LEISTNER, Rodrigo M. Caminhos trancados: Conflitos e projetos políticos afroreligiosos e o processo eleitoral no Rio Grande do Sul. Debates do NER, Porto Alegre, v. II, n. 18, p. 129-148, jul./dez. 2010.

BOHN, Simone R. Evangélicos no Brasil: Perfil socioeconômico, afinidades ideológicas e determinantes do comportamento eleitoral. Opiniáo Pública, Campinas, v. 10, n. 2, p. 288-338, out. 2004.

BOHRNSTEDT, George G.; KNOKE, David. Statistics for social data analysis. New York: Peacock, 1982.

CAMPBELL, David E. Acts of faith: Churches and political engagement. Political Behavior, v. 26, n. 2, p. 155-180, 2004.

CORTEN, André. Os pobres e o Espírito Santo: O pentecostalismo no Brasil. Petrópolis: Vozes, 1996.

DJUPE, Paul A.; GRANT, J. Tobin. Religious institutions and political participation in America. Journal of Scientific Study of Religion, v. 40, n. 2, p. 302-314, 2001.

FRESTON, Paul. Protestantes e Politica no Brasil: Da Constituinte ao Impeachment. 1993. Tese (Doutorado em Ciências Sociais) - Programa de Pós-Graduação em Ciências Sociais, Universidade de Campinas, Campinas, 1993.

GIUMBELLI, Emerson. O fim da religião: dilemas da liberdade religiosa no Brasil e na França. São Paulo: Attar Editorial, 2002. 
INGLEHART, Ronald; CATTERBERG, Gabriela. Trends in political action: the development trend the post-honeymoon decline. International Journal of Comparative Sociology, Toronto, v. 43, n. 3-5, p. 300-316, 2002.

INGLEHART, Ronald; WELZEL, Christian. Modernização, mudança cultural e democracia: a sequência do desenvolvimento humano. São Paulo: Francis, 2009.

JONES-CORREA; Michael, LEAL, David. Political participation: Does religion matter? Political Research Quarterly, n. 4, p. 751-770, dez. 2001.

LAPOP. Latin American Public Opinion Project. 2012. Disponível em: <www.lapopsurveys.org>. Acesso em: jul. 2005.

MARIANO, Ricardo. Laicidade à brasileira. Católicos, pentecostais e laicos em disputa da esfera pública. Civitas, Porto Alegre, v. 11, n. 2, p. 238-258, maio-ago. 2011.

MONTERO, Paula. Religião, pluralismo e esfera pública no Brasil. Novos Estudos CEBRAP, São Paulo, n. 74, p. 47-65, mar. 2006.

MONTERO, Paula. Controvérsias religiosas e esfera pública: repensando as religióes como discurso. Religião e Sociedade, Rio de Janeiro, v. 32, n. 1, p. 167-183, 2012.

ORO, Ari. Religião e Política nas Eleiçóes 2000 em Porto Alegre (RS). Debates do NER, Porto Alegre, v. 2, n. 3, p. 9-70, set. 2001.

ORO, Ari. A política da Igreja Universal e seus reflexos nos campos religiosos e políticos brasileiros. Revista Brasileira de Ciências Sociais, v. 18, n. 53, p. 53-69, out. 2003.

ORO, Ari; MARIANO, Ricardo. Eleiçôes 2010: Religião e Política no Rio Grande do Sul e no Brasil. Debates do NER, Porto Alegre, v. II, n. 18, p. 11-38, jul./dez. 2010.

PIERUCCI, Antônio F. Eleição 2010: Desmoralização eleitoral do moralismo religioso. Novos Estudos - CEBRAP, São Paulo, n. 89, p. 5-15, mar. 2011.

POWERS, Daniel; XIE, Yu. Statistical Methods for Categorical Data Analysis. 2a.ed. London: Emerald Group Publishing Ltd, 2008.

PUTNAM, Robert. Making Democracy Work: Civic Traditions in Modern Italy. Princeton, USA: Princeton University Press, 1993.

PUTNAM, Robert. Bowling Alone: The Collapse and Revival on American Community. New York: Simon \& Schuster, 2000.

RIBEIRO, Ednaldo; BORBA, Julian. Participação Política na América Latina. Maringá: Eduem, 2015. VERBA, Sidney; SCHLOZMAN, Kay L.; BRADY, Henry E. Voice and Equality: Civic Volunteerism in American Politics. Cambridge, USA: Harvard University Press, 1995. 